Article

\title{
Investigation of Mechanical Loads Distribution for the Process of Generating Gear Grinding
}

\author{
Patricia de Oliveira Teixeira ${ }^{1, *}$, Jens Brimmers ${ }^{1}(\mathbb{D})$ and Thomas Bergs ${ }^{1,2}$ \\ 1 Laboratory of Machine Tools and Production Engineering (WZL), RWTH Aachen University, \\ Campus Boulevard 30, 52074 Aachen, Germany; j.brimmers@wzl.rwth-aachen.de (J.B.); \\ t.bergs@wzl.rwth-aachen.de (T.B.) \\ 2 Fraunhofer Institute for Production Technology (IPT), Steinbachstraße 17, 52074 Aachen, Germany \\ * Correspondence: p.oliveira_teixeira@wzl.rwth-aachen.de
}

check for

updates

Citation: de Oliveira Teixeira, P.; Brimmers, J.; Bergs, T. Investigation of Mechanical Loads Distribution for the Process of Generating Gear Grinding. J. Manuf. Mater. Process. 2021, 5, 13. https://doi.org/ 10.3390/jmmp5010013

Received: 29 November 2020

Accepted: 22 January 2021

Published: 27 January 2021

Publisher's Note: MDPI stays neutra with regard to jurisdictional claims in published maps and institutional affiliations.

Copyright: (c) 2021 by the authors. Licensee MDPI, Basel, Switzerland. This article is an open access article distributed under the terms and conditions of the Creative Commons Attribution (CC BY) license (https:// creativecommons.org/licenses/by/ $4.0 /)$.

\begin{abstract}
In grinding, interaction between the workpiece material and rotating abrasive tool generates high thermo-mechanical loads in the contact zone. If these loads reach critically high values, workpiece material properties deteriorate. To prevent the material deterioration, several models for thermomechanical analysis of grinding processes have been developed. In these models, the source of heat flux is usually considered as uniform in the temperature distribution calculation. However, it is known that heat flux in grinding is generated from frictional heating as well as plastic deformation during the interaction between workpiece material and each grain from the tool. To consider these factors in a future coupled thermomechanical model specifically for the process of gear generating grinding, an investigation of the mechanical load distribution during interaction between grain and workpiece material considering the process kinematics is first required. This work aims to investigate the influence of process parameters as well as grain shape on the distribution of the mechanical loads along a single-grain in gear generating grinding. For this investigation, an adaptation of a single-grain energy model considering the chip formation mechanisms is proposed. The grinding energy as well as normal force can be determined either supported by measurements or solely based on prediction models.
\end{abstract}

Keywords: grinding; mechanical loads; modeling

\section{Introduction}

Generating gear grinding is a hard finishing process mainly used to meet the high requirements for gears in terms of geometry and surface quality [1]. During grinding, a major percentage of the generated energy is converted into heat [2]. The generated heat is distributed mainly into four regions: Environment, tool (grinding worm), chip, and workpiece, middle of Figure 1. Depending on the process condition, a fraction of $60-90 \%$ of the generated heat can flow into the workpiece [3]. This fraction of generated heat leads to high temperatures in the contact zone, which can cause thermal damages in the workpiece such as metallurgical phase transformations and undesirable residual stress profiles $[4,5]$.

In order to better understand and control the part of the generated heat that flows into the workpiece, it is first necessary to specify the according energy partition. In the work of Hahn it was established that the removal of material by each grain of the grinding tool during the process is performed during three different phases: Friction, plowing, and shearing [6,7]. Each of these phases contributes in a singular way to the partition of energy that goes to the workpiece [5,7]. From heat transfer considerations it was shown that almost all the energy generated in the friction phase was conducted as heat to the workpiece [5]. In addition, only a fraction of the complete energy generated in the plowing phase was conducted to the workpiece [5]. Regarding the energy generated in the shearing phase, it was shown that about $45 \%$ of this energy was conducted as heat to the workpiece [5]. The energy generated in each of the three phases of material removal is significantly 
influenced by characteristics of the grinding process such as process parameters, grinding tool specification, and workpiece material. Therefore, understanding the energy generation in each of the three phases of material removal is an important tool not only for the control of heat partition to the workpiece but also for the definition of a suitable process design.

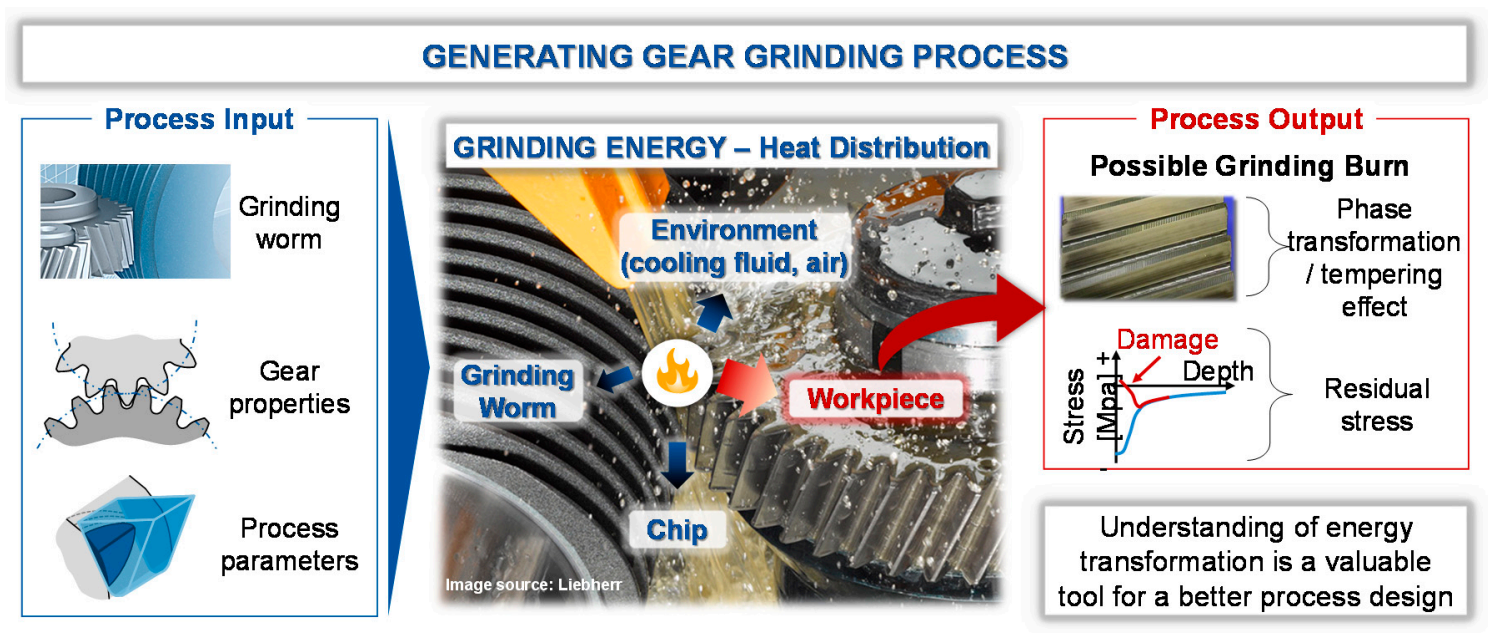

Figure 1. Distribution of energy during the process of grinding.

In this work, an adaptation of a single-grain energy model considering the chip formation mechanisms is proposed. The adaptation will be performed on an already existing single-grain model and based on the use of data obtained from experimental trials. One of the measurement values obtained from experimental trials which will be used for the single-grain energy adaptation is the normal force. The grinding energy as well as the normal force can be determined either supported by measurements or solely based on prediction models. In previous research, a model for the calculation of normal force was presented, taking into consideration the tool topography for the process of generating gear grinding [8]. In the future, the normal force model developed in [8] can be used as an input for the adapted single-grain energy model developed in the current work. Ultimately, prediction and analysis of the energy in grinding considering the chip formation mechanisms can lead to better understanding of the generated heat flowing into the workpiece and to a better process design.

For the development of a procedure for single-grain energy modeling considering chip formation mechanisms, it is first essential to comprehend the existing models and verify their advantages as well as their limitations. The modeling of the chip formation mechanisms in a grinding energy model can be very challenging due to the partition of the different influencing factors involved. Therefore, a careful look into the existing models is required.

\subsection{Classical Energy Models}

The interaction between the grains of the grinding tool and the workpiece during grinding is very complex due to the singularities of the process [9]. An analysis of the cutting mechanisms of one grain during the process shows that the thickness of the removed material changes according to the position of the grain in the contact zone $[10,11]$. At the end of the contact zone, the grain engagement is maximum, producing maximum chip thickness. Due to the change in the chip thickness in addition to the very small chips produced, cutting mechanisms for conventional cutting with a defined cutting edge cannot be used to explain the cutting mechanisms occurring in grinding processes [11]. The cutting mechanisms occurring during the chip formation in grinding with a single grain can be divided into three phases: Friction, plowing, and shearing (upper right of Figure 2) [6]. The starting location of each of the three phases is defined according to the grain depth of cut along the contact length [12]. 


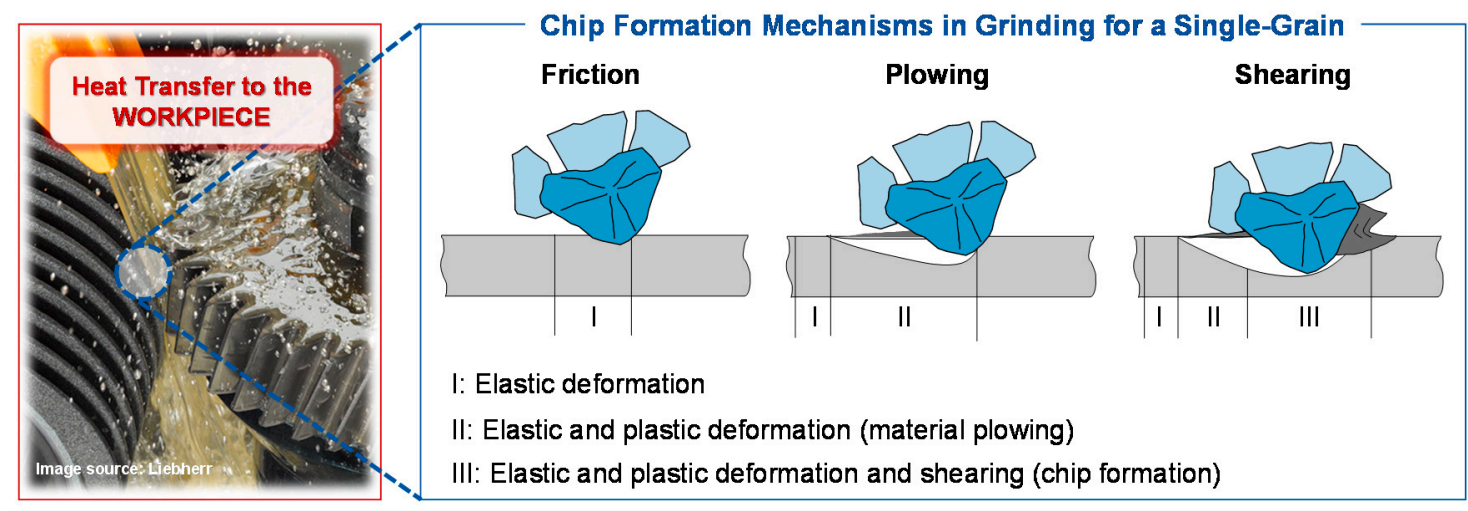

Consideration of chip formation mechanisms on the energy modeling of grinding process can

improve the understanding of the heat transferred to the workpiece during the process

Figure 2. Chip formation mechanisms for the process of grinding.

The first chip formation mechanism refers to the energy required to overcome friction between grain and workpiece. Due to this, this mechanism is called friction and it occurs throughout the entire engagement between grain and workpiece. The friction mechanism considers only the elastic deformation during the material removal $[6,10]$. If the grain depth of cut increases to a critical value, the second mechanism, plowing, begins. Plowing energy refers to the energy required to deform and plow material. The plowing mechanism occurs up to a certain critical depth until the end of the contact length and it considers the plastic deformation during the material removal $[6,10]$. Further increasing the grain depth of cut until a critical value, the third mechanism, shearing, begins. Shearing energy refers to the energy required to form the chip and it considers the chip formation by means of the material shearing $[6,10]$.

In the past years, several models for the analysis of energy in grinding process based on the three phases of chip formation mechanisms have been developed. Kopalinsky, for example, developed a two-dimensional analytical model for grain material removal and friction by approximating the active abrasive grains as small orthogonal cutting tools with negative rake angles [13]. The model was able to estimate the contribution of friction of dull grains on the grinding forces. Park et al. proposed a predictive model of grinding force considering plowing and shearing forces [14]. Friction, or sliding force, were not considered in their model. The plowing force was considered based on Brinell hardness indentation tests and the shearing force was considered based on the Merchant theory. The model was able to predict the total grinding power in cylindrical grinding. Durgumahanti et al. developed a grinding force model considering the effect of friction and plowing force [15]. A series of empirical coefficients were introduced and determined experimentally for both frictional force component and plowing force component. It was shown that the plowing force becomes more predominant at very low depths of cut.

Linke et al. proposed a simplified distributed grain model, incorporating the three phases of material removal depending on engagement depth [3]. The calculation of energy of each of the three phases was performed based on analytical models and literature studies. The model developed by Linke et al. is comparable to other models from the literature, with the advantage of being able to be applied to grinding processes with different kinematics [3]. Due to these two characteristics, simplicity and flexibility to different process kinematics, the model proposed by Linke et al. will be further analyzed in the current work. The basis of energy model proposed by Linke et al. is shown in Equation (1) [3]. The calculation of total single-grain energy consists of the sum of the energies of each of the three phases of chip formation mechanisms: Friction, plowing, and shearing.

$$
E_{\text {total }}=\int_{0}^{a_{e}} E_{f r}(t) d t+\int_{T_{p l}}^{a_{e}} E_{p l}(t) d t+\int_{T_{\text {sh }}}^{a_{e}} E_{s h}(t) d t
$$


where

- $\mathrm{E}_{\text {total }}$ is the total grinding energy [J]

- $\mathrm{E}_{\mathrm{fr}}$ is the friction energy [J]

- $\mathrm{E}_{\mathrm{pl}}$ is the plowing energy [J]

- $\mathrm{E}_{\mathrm{sh}}$ is the shearing energy [J]

- $\mathrm{a}_{\mathrm{e}}$ is the depth of cut [mm]

- $\mathrm{t}$ is the time [s]

- $\mathrm{T}_{\mathrm{pl}}$ is the critical depth of cut for plowing [mm]

- $\mathrm{T}_{\mathrm{sh}}$ is the critical depth of cut for shearing [mm]

Next, an individual energy model for each phase of chip formation is determined. The calculation for the friction energy $E_{f r}$ is shown in the Equation (2). The friction energy $E_{f r}$ is calculated as the product of contact length $l_{c}$ and grain normal force $F_{n \text {,grain }}$. The grain normal force can be obtained by means of force models or measurements of experimental trials. The contact length $l_{c}$ represents the distance of the entire engagement between grain and workpiece. As already established before, the friction energy $\mathrm{E}_{\mathrm{fr}}$ happens along the entire engagement between grain and workpiece. Due to this, the integral for $E_{f r}$ is calculated from 0 , beginning of contact, until ae, end of contact.

$$
E_{f r}=\int_{0}^{a_{e}} F_{n, \text { grain }} \cdot l_{c}(t) d t
$$

where

- $\quad \mathrm{E}_{\mathrm{fr}}$ is the friction energy [J]

- $\mathrm{a}_{\mathrm{e}}$ is the depth of cut [mm]

- $\mathrm{F}_{\mathrm{n}, \text { grain }}$ is the normal force per grain [mm]

- $1_{\mathrm{c}}$ is the contact length $[\mathrm{m}]$

In simplified models, the calculation of the plowing energy is approximated to the indentation hardness $\mathrm{H}$ of the material being plowed $[3,12]$. However, this approximation is not entirely suitable for the grain engagement because it does not consider the grain shape. Therefore, an adaptation of the energy model was performed by Linke et al. in their model [3]. In Equation (3) it is shown that the plowing energy is calculated from the area of displacement $A_{p l}$ multiplied by the material hardness $\mathrm{H}$ and the contact length $\mathrm{l}_{\mathrm{c}}$. The integral for $\mathrm{E}_{\mathrm{pl}}$ is calculated from critical depth of cut for plowing $\mathrm{T}_{\mathrm{pl}}$ until $\mathrm{a}_{\mathrm{e}}$, end of grain engagement. In their work, Jiang et al. investigated the critical depth of cut for plowing $\mathrm{T}_{\mathrm{pl}}$ based on the Hertz contact theory [12]. It was shown that plowing begins at a depth of cut so small that $\mathrm{T}_{\mathrm{pl}}$ can be approximated to 0 . In this work the critical depth of cut for plowing $\mathrm{T}_{\mathrm{pl}}$ will be considered as 0 .

$$
\mathrm{E}_{\mathrm{pl}}=\int_{\mathrm{T}_{\mathrm{pl}}}^{\mathrm{a}_{\mathrm{e}}} \mathrm{A}_{\mathrm{pl}}(\mathrm{t}) \cdot \mathrm{H} \cdot \mathrm{l}_{\mathrm{c}}(\mathrm{t}) \mathrm{dt}
$$

where

- $\quad \mathrm{E}_{\mathrm{pl}}$ is the plowing energy [J]

- $\mathrm{a}_{\mathrm{e}}$ is the depth of cut [mm]

- $\mathrm{T}_{\mathrm{pl}}$ is the critical depth of cut for plowing [mm]

- $\mathrm{A}_{\mathrm{pl}}$ is the plowing contact $\left[\mathrm{mm}^{2}\right]$

- $\mathrm{H}$ is the hardness $\left[\mathrm{N} / \mathrm{mm}^{2}\right]$

- $\mathrm{l}_{\mathrm{c}}$ is the contact length $[\mathrm{m}]$

Next, the energy fraction for shearing is defined, Equation (4). The calculation of the shear energy $E_{s h}$ is performed by the multiplication between the shear strength $S$, sheared cross-sectional area and contact length $1_{c}$. The cross-sectional area is calculated from the grain width $b_{c u}$ multiplied by the shear height $h_{\text {shear }}$. The integral for $E_{s h}$ is calculated from critical depth of cut for shearing $\mathrm{T}_{\mathrm{sh}}$ until ae, end of grain engagement. In this work, 
the critical depth of cut for shearing $\mathrm{T}_{\text {sh }}$ will be defined as $2.5 \%$ of the cutting depth $\mathrm{a}_{\mathrm{e}}$, according to the work of Jiang et al. [12].

$$
E_{\text {sh }}=\int_{T_{\text {sh }}}^{a_{\mathrm{e}}} S \cdot b_{\text {cu }} \cdot h_{\text {shear }} \cdot l_{c}(t) d t
$$

where

- $\mathrm{E}_{\mathrm{sh}}$ is the shearing energy [J]

- $\mathrm{T}_{\mathrm{sh}}$ is the critical depth of cut for shearing [mm]

- $\mathrm{S}$ is the shear strength $[\mathrm{MPa}]$

- $\mathrm{b}_{\mathrm{cu}}$ is the grain width [mm]

- $\mathrm{h}_{\mathrm{sh}}$ is the shear height [mm]

- $\mathrm{l}_{\mathrm{c}}$ is the contact length $[\mathrm{m}]$

The model developed by Linke et al. presents a simple and flexible solution for singlegrain total energy $\mathrm{E}_{\text {total }}$ modeling, considering all the chip formation mechanisms [3]. The input parameters for the model can be obtained from the literature as well as from experimental trials or process simulation tools. Therefore, the model was selected to be further analyzed in the current work.

\subsection{Objective}

The understanding of each chip formation mechanism influence on the energy generated in grinding is important to better understand and control the part of the generated heat that flows into the workpiece. The objective of the current work is presented in Figure 3. The main objective of the work is the adaptation of a single-grain energy model considering contributions of specific energies from chip formation mechanisms. The research will be focused on the investigation of the single-grain energy model developed by Linke et al. and its adaptation by means of the consideration of results obtained from experimental single-grain trials, Figure 3. In order to achieve the objective proposed, the current work will be divided into 3 phases, Figure 3. In Phase 1, single-grain trials will be conducted, considering the influence of process parameters and grains shape. In Phase 2, the single-grain energy model from Linke will be adapted by means of the development of a procedure based on the results obtained from single-grain experimental trials. In Phase 3 , the results of the adapted single-grain energy model will be analyzed and compared to the energy calculated from the force measurements obtained from the single-grain experimental trials. In the end, a validation of the adapted single-grain energy model is expected to be obtained.

Objective
Adaptation of a single-grain energy model considering the contributions of the
specific energies from the chip formation mechanisms

\section{Phase 1: Experimental Trials}

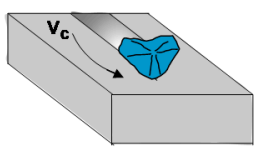

Design of experiments and execution of single-grain trials
Phase 2: Adaptation of Energy Model

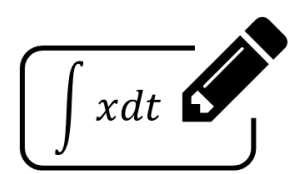

Adaptation of an existing energy model by considering results from single-grain trials
Phase 3: Validation and Application of Energy Model

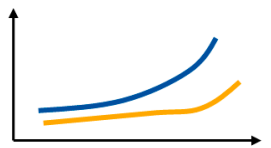

Analysis of the single-grain trials and investigation and validation of the adapted energy model

Figure 3. Objective and approach of the work. 


\section{Materials and Methods}

In order to be able to consider the influence of process parameters and grains shape in the model in phase 1, experimental trials were conducted. The trials were performed based on the single-grain trials executed in the research presented in previous works [8]. In the current experimental trial, a more detailed investigation of the grain shape was performed in comparison to the trials previously performed.

The trials were performed on a surface grinding machine Blohm 6000, Figure 4. Corundum grains with a grit size of F80 were used. The single grain was placed in a holder, bottom of Figure 4. The holder was fixed in a screw, which was fixed in an aluminum wheel with diameter of $\mathrm{ds}=400 \mathrm{~mm}$, simulating a surface grinding wheel. For each test point of the design of experiments, a new grain was used.

Description of Trials
Workpiece:
q $20 \mathrm{MnCr} 5$
- Case Hardened
Grain:
- Corundum
- F80
Extra Information:
- Tests performed in a
surface grinding
machine
n No lubricant

Description of Trials

Workpiece:

- Case Hardened

Grain:

- Corundum

Extra Information:

surface grinding
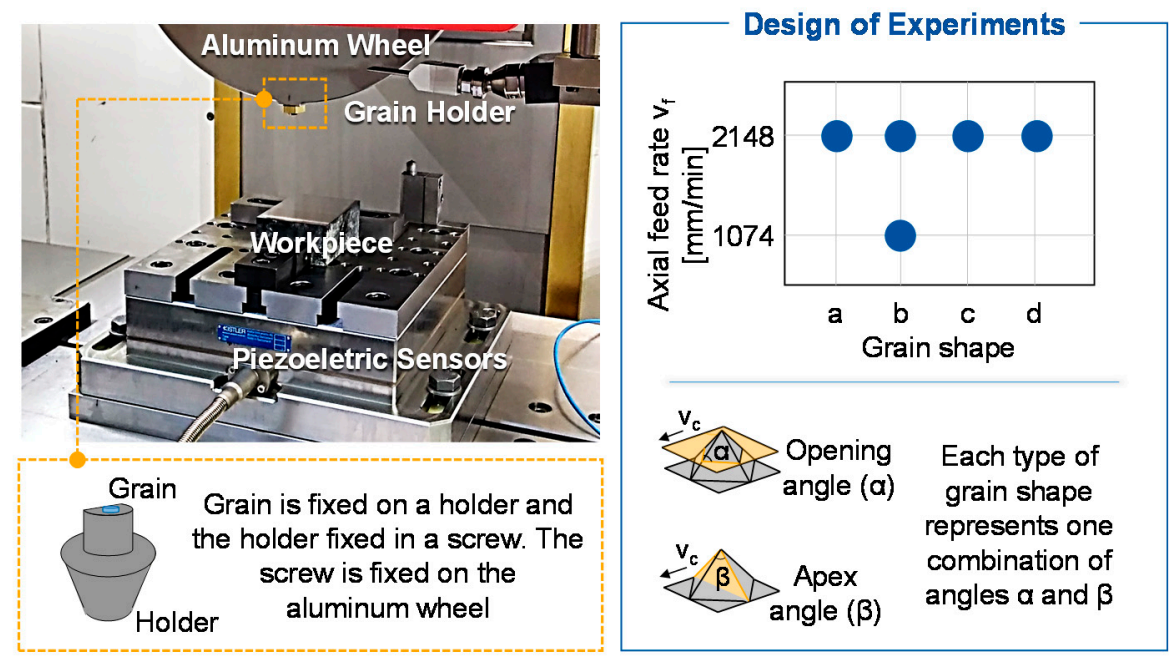

Figure 4. Description of experimental procedure and design of experiment.

For the trials, the workpiece was a block with length of $1=100 \mathrm{~mm}$, width of $b=70 \mathrm{~mm}$, and height of $h=39 \mathrm{~mm}$, of case hardened $20 \mathrm{MnCr} 5$ with $60 \mathrm{HRC}$. The workpiece was preground in order to obtain a smoother surface $\left(R_{a}=0.15 \mu \mathrm{m}\right.$ and $\left.R_{z}=1.18 \mu \mathrm{m}\right)$. The workpiece was fixed on the top of a measurement platform of piezoelectric sensors from Minidyn 9256C 1 type from the company Kistler Instruments, with a sample rate of $f=1 \mathrm{MHz}$, for the assessment of normal force during the trials. The single-grain trials represented a surface grinding process with only one grain. In the single-grain trials two factors were varied, axial feed rate $\mathrm{v}_{\mathrm{f}}$ and grain shape. The axial feed rate was varied was varied in two levels, $\mathrm{v}_{\mathrm{f} 1}=2148 \mathrm{~mm} / \mathrm{min}$ and $\mathrm{v}_{\mathrm{f} 2}=1074 \mathrm{~mm} / \mathrm{min}$. The cutting speed was kept constant at $\mathrm{v}_{\mathrm{C}}=45 \mathrm{~m} / \mathrm{s}$

In addition, the grains shape was also analyzed in terms of cutting angles, lower right of Figure 4 . The cutting angles from the grains were determined by means of measurements with a confocal microscope of the company Keyence, model VK-X 100. Four types of grain shapes were analyzed, described as a, b, c, and d, in the right of Figure 4. The grain shapes $\mathrm{a}$ and $\mathrm{b}$ vary the opening angle $\alpha$, while keeping the apex angle $\beta$ constant. The grain shapes $\mathrm{c}$ and $\mathrm{d}$ vary the apex angle $\beta$ while keeping the opening angle $\alpha$ constant. In this way, the influence of the grain shape in terms of grain cutting angle on the results of the adapted energy model were verified.

\section{Adaptation of Energy Model}

Next, the adaptation of the Linke single-grain energy model was performed in Phase 2. First, the calculation of the friction energy $E_{\mathrm{fr}}$ was analyzed. As already established, $\mathrm{E}_{\mathrm{fr}}$ is calculated as the product of normal force $F_{n}$ and contact length $1_{c}$. $E_{f r}$ was calculated following three steps, left of Figure 5. 


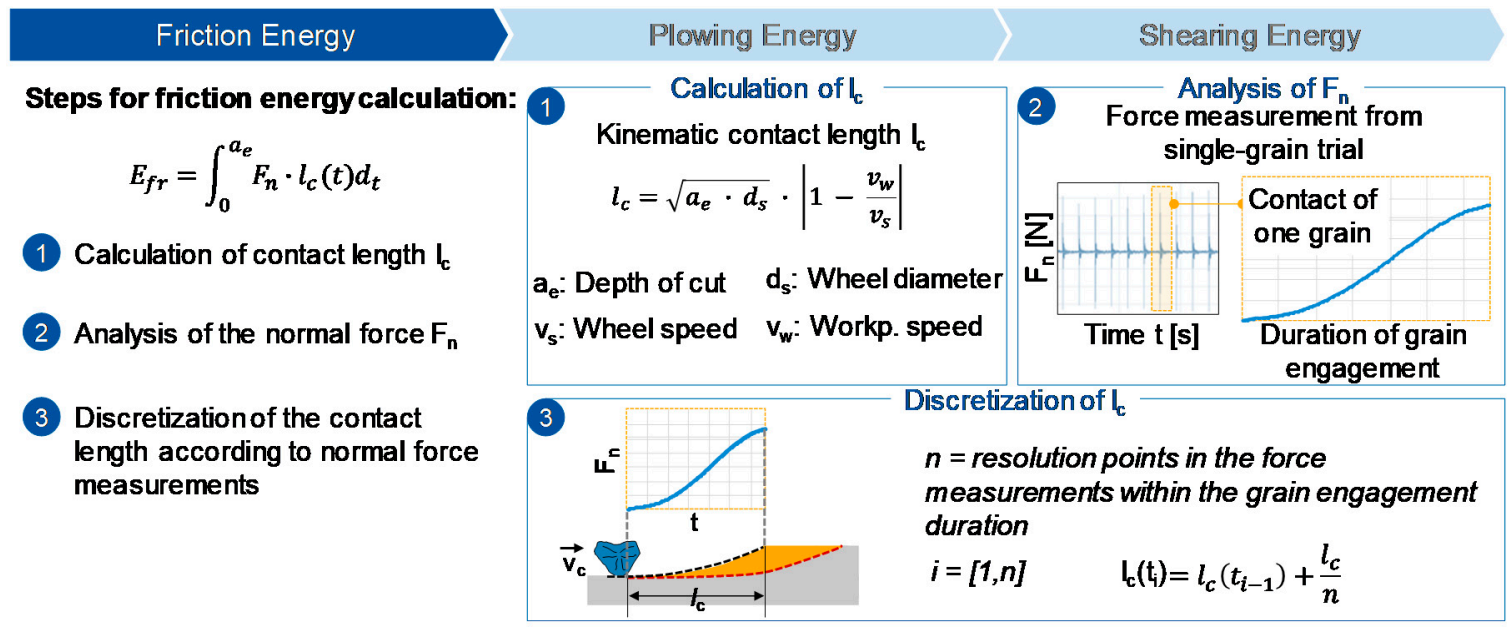

Figure 5. Modeling of friction energy.

The first step was the calculation of the kinematic contact length $1_{c}$, applying the formula shown in the upper middle of Figure 5 [16]. In the second step, the force measurements from the single-grain trials were analyzed, upper right of Figure 5. Each peak in the force measurement corresponds to one engagement, of the grain with the workpiece. Considering the process parameters used in the single-grain trial, the duration required for the grain to go through the entire contact length $l_{c}$ was calculated. This duration helped to define the beginning and the end of the contact length in the force curve, as shown in the right of Figure 5 . The end of the contact length $l_{\mathcal{C}}$ is always at one peak point in the force measurement. The third step for the calculation of friction energy $E_{f r}$ was the discretization of the contact length $l_{c}$ according to the number of points from the force measurement within the grain engagement duration $n$. This step is explained at the bottom of Figure 5. The discretization of the contact length $l_{c}$ was performed in order to calculate the integral of the friction energy $E_{\mathrm{fr}}$. After the execution of the three steps, the friction energy $E_{\mathrm{fr}}$ could be calculated.

Next, the calculation of the plowing energy $\mathrm{E}_{\mathrm{pl}}$ was analyzed. As already established, $\mathrm{E}_{\mathrm{pl}}$ was calculated as the product of plowing area $\mathrm{A}_{\mathrm{pl}}$, the contact length $\mathrm{l}_{\mathrm{c}}$ and the material hardness $\mathrm{H}$. In the same way as in the calculation of the friction energy $\mathrm{E}_{\mathrm{fr}}$, the contact length also needs to be discretized for the integral calculation of the plowing energy $\mathrm{E}_{\mathrm{pl}}$. For obvious reasons, the same contact length $l_{c}$ discretization used in $E_{f r}$ was also used for $E_{\mathrm{pl}}$. Therefore, only one extra step was required for the calculation of the plowing energy $E_{p l}$, the calculation of plowing area $A_{p l}$. A description of the plowing energy $E_{p l}$ calculation as well as of the plowing area $A_{p l}$ calculation can be found in Figure 6 .

The plowing area $A_{p l}$ is defined as the area of displacement during the grain engagement. For simplification of calculation, the plowing area $A_{p l}$ can be represented by the grain cross-section area, which it is assumed to be the area of displacement during the grain engagement. Originally, the grain cross-section area can be determined by means of measurements of the grain profile in cutting speed direction with confocal microscope. However, due to the uncertainty in the positioning of the grain in the grinding machine for the single-grain experimental trial, the grain profile in cutting speed direction measured with the microscope might differ from the actual grain profile from the experimental trials. In order to reduce the influence of this uncertainty on the determination of the plowing area $A_{p l}$, the calculation of plowing area $A_{p l}$ considers not only the grain profile in cutting speed but also the grain scratch profile in the workpiece, upper right of Figure 6. The grain scratch profile is determined by means of measurement of the grain scratch with the confocal microscope. The grain scratch profile and the grain profile are analyzed in terms of their cross-section area and a factor $q$ is determined by means of the average between both cross-section areas. The factor $\mathrm{q}$, representing the average between both cross-section areas analyzed, is used as the plowing area $\mathrm{A}_{\mathrm{pl}}$ for the calculation of the plowing energy $\mathrm{E}_{\mathrm{pl}}$. In 
the same way as the contact length $1_{c}$, the plowing area $A_{p l}$ needs to be discretized for the integral calculation of the plowing energy $\mathrm{E}_{\mathrm{pl}}$. The calculation of the discretized plowing area $A_{p l}$ was performed according to the resolution points $\mathrm{n}$ in the force measurements within the grain engagement duration. The calculation of the discretized plowing area $A_{p l}$ was performed with the support of a routine written in the software MATLAB. The routine required as input a $2 \mathrm{D}$ profile of the grain scratch, the factor $\mathrm{q}$ and the number $\mathrm{n}$ of discretization points, lower right of Figure 6. The output of the routine was the plowing area $A_{p l}$ for each discretization point along the contact length, as displayed in the lower right of Figure 6. At the beginning of the grain engagement (beginning of the contact length $1_{c}$ ) the grain scratch cross-section area is at its minimum value. As the grain approaches the end of the engagement (end of contact length $1_{c}$ ), the chip thickness increases as well as the grain scratch cross-section area. At the end of the grain engagement, the grain scratch cross-section area is at its maximum value. After the execution of calculation of the discretized plowing area, the plowing energy $\mathrm{E}_{\mathrm{pl}}$ could be calculated.

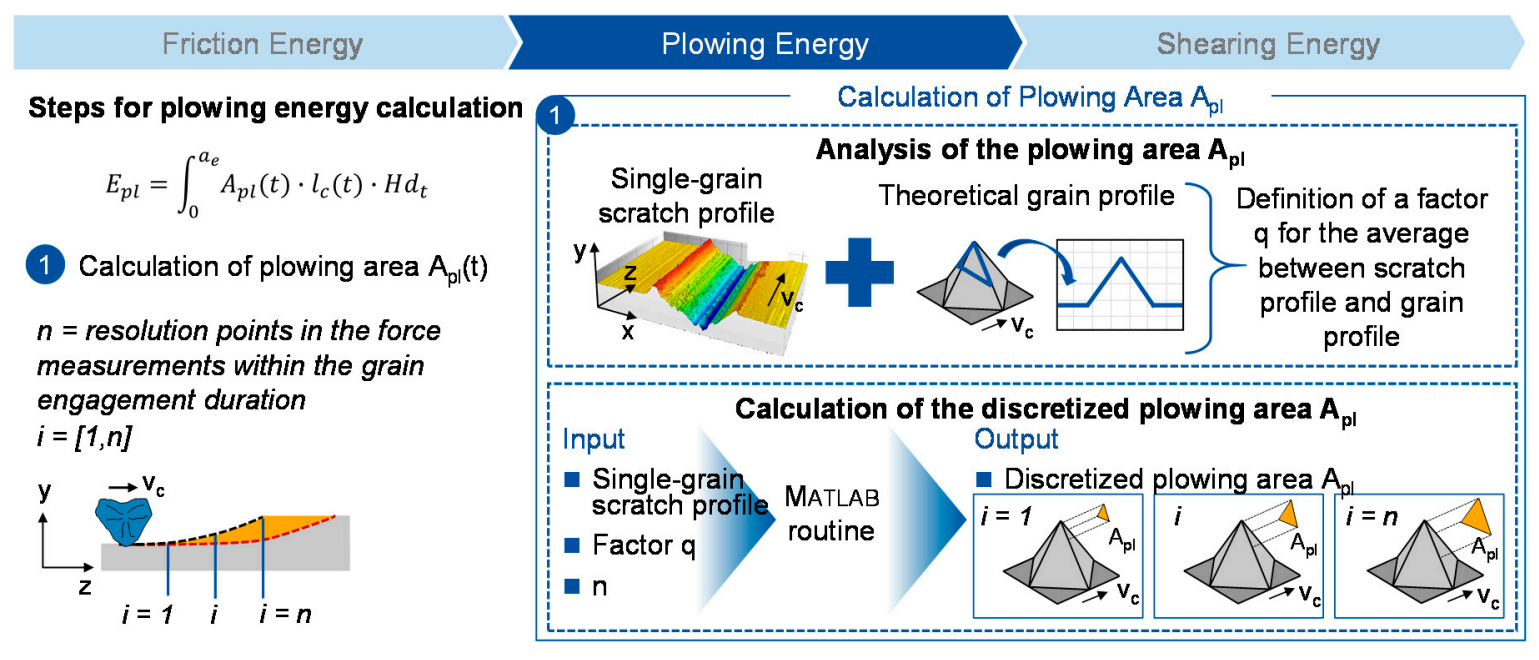

Figure 6. Modeling of plowing energy.

Next, the calculation of the shearing energy $\mathrm{E}_{\mathrm{sh}}$ was analyzed. As already established, $\mathrm{E}_{\mathrm{sh}}$ is calculated as the product of shear force $\mathrm{F}_{\text {shear }}$, and the contact length $\mathrm{l}_{\mathrm{c}}$, Figure 7 . The same contact length $1_{c}$ discretization used in $E_{f r}$ and $E_{p l}$ was also used for $E_{s h}$. The shear force $F_{\text {shear }}$ is calculated by the product of the shear strength $S$, grain width $b_{c u}$ and shear height $h_{\text {shear }}$. The calculation of shear height $h_{\text {shear }}$ is shown on the upper right of Figure 7 . Differently from the other two energies calculated so far, $E_{\mathrm{fr}}$ and $\mathrm{E}_{\mathrm{pl}}$, the integral for the shearing energy $E_{\mathrm{sh}}$ calculation does not begin at 0 . It begins at the critical depth of cut for shearing $\mathrm{T}_{\text {sh }}$, defined as $2.5 \%$ of the cutting depth $\mathrm{a}_{\mathrm{e}}$, according to the work of Jiang et al. [10]. The shear height $h_{\text {shear }}$ was calculated dividing the chip thickness $h_{c u}$ by the sine of shear angle $\Phi$. According to Brown the shear angle $\Phi$ is calculated based on the friction angle and grain rake angle [17]. The friction angle is calculated as the arctangent of the friction coefficient of the contact between grain and workpiece [16]. In this report, the grain rake angle was measured with the confocal microscope. With the values of friction angle and grain rake angle, the shear angle $\Phi$ was calculated, and ultimately, the shear height $h_{\text {shear }}$ was calculated. For the calculation of shear force $F_{\text {shear }}$, the next step is to calculate the grain width $b_{c u}$. The grain width $b_{c u}$ is calculated based on the single-grain scratch profile, as shown on the lower right of Figure 7.

For the calculation of the grain width $b_{c u}$, the MATLAB routine used for the determination of the plowing area $\mathrm{A}_{\mathrm{pl}}$, shown on the calculation of plowing energy $\mathrm{E}_{\mathrm{pl}}$, was adapted. In this adaptation, the grain width $b_{c u}$ is calculated from the measured 2D profile of the grain scratch, as shown in Figure 7. In addition, in the same way as the contact length $l_{c}$, the grain width $b_{c u}$ needs to be discretized for the integral calculation of the 
shearing energy $E_{\mathrm{sh}}$. The calculation of the discretized grain width was also performed by the MATLAB routine already mentioned.

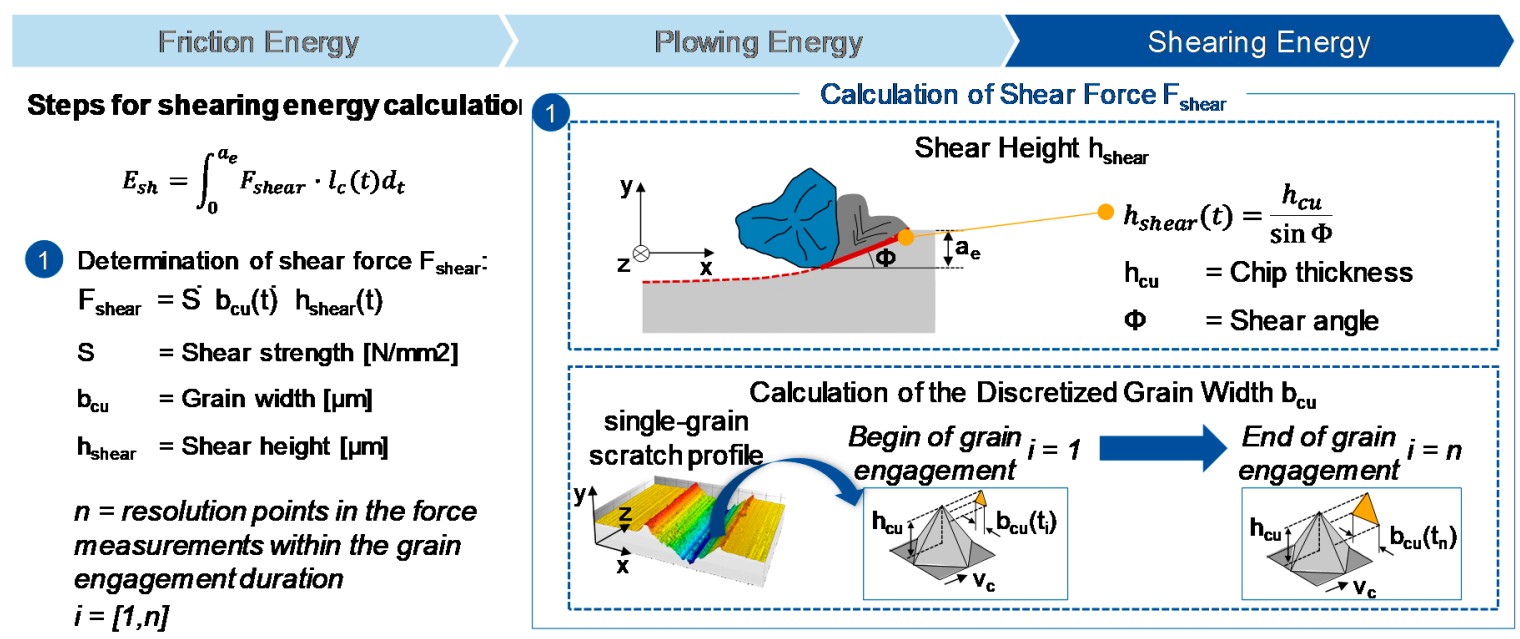

Figure 7. Modeling of shearing energy.

\section{Results}

\subsection{Validation of the Adapted Energy Model}

After the execution of the experimental single-grain trials and the implementation of the results on the adapted Linke single-grain energy model, the validation of the model is shown in this topic, according to the phase 3 . The validation of the adapted energy model was performed by means of the comparison between the total energy $E_{\text {total }}$, calculated with the adapted Linke energy model, Equation (1), and the grinding energy $E_{\text {gri }}$, calculated from the force measurements obtained from the single-grain experimental trials. In general, energy can be described by the product of power P and time $t$ [18]. Power P can be simply described as the product of total force $\mathrm{F}$ and cutting speed $\mathrm{v}_{\mathrm{c}}$. Therefore, the calculation of the grinding energy $E_{\text {gri }}$ was performed by the product of the measured total force $F_{c}$, the cutting speed $v_{c}$ and the contact time $t_{k}$, as shown in Equation (5) [18]. All these three parameters were obtained in the experimental single-grain trials.

$$
\mathrm{E}_{\text {gri }}=\mathrm{F}_{\mathrm{c}} \cdot \mathrm{v}_{\mathrm{c}} \cdot \mathrm{t}_{\mathrm{k}}
$$

where

- $\quad E_{\text {gri }}$ is the grinding energy [J]

- $\mathrm{F}_{\mathrm{C}}$ is the total force $[\mathrm{N}]$

- $\quad \mathrm{v}_{\mathrm{c}}$ is the cutting speed $[\mathrm{m} / \mathrm{s}]$

- $t_{k}$ is the contact time [s]

Comparing the results obtained from the adapted Linke single-grain energy model to the grinding energy $\mathrm{E}_{\text {gri }}$, a direct comparison between the results of the adapted energy model and the measurements of the single grain trials is possible. In the right side of Figure 8, two diagrams are shown, with five energy curves during the grain engagement time. The curves represent the three energies of each of the three phases of chip formation mechanisms (friction, plowing, and shearing), the total energy $E_{\text {total }}$ (which is the sum of the individual energies of the three phases) and the grinding energy $E_{\text {gri }}$. All the energy curves, with exception of the grinding energy $E_{\text {gri }}$, were calculated using the method explained in topic 2.1 based on the adapted Linke single-grain energy model.

In both diagrams at the upper right of Figure 8, representing Trials 1 and 2, a good correlation between the grinding energy $E_{\text {gri }}$ and the total energy $E_{\text {total }}$ was found. Only at the end of the curve, a small difference between both energies was observed, and the total energy $E_{\text {total }}$ was slightly higher than the grinding energy $E_{\text {gri }}$. The difference between the 
total energy $E_{\text {total }}$ and the grinding energy $E_{\text {gri }}$ can be attributed to the plowing and/or shearing energies. For the calculation of plowing and shearing energy, an assumption was made regarding the calculation of the grain cross-section area and grain width. Although this assumption has advantages, it might also induce to small errors, which are seen in the end of the energy curves in the diagrams of Figure 8. The adapted Linke single-grain model is suitable for the calculation of energy during single-grain processes.

\section{Description of Trials}

Trial 1:

- $\mathrm{v}_{\mathrm{c}}=45 \mathrm{~m} / \mathrm{s}$

- $v_{\mathrm{f}}=2148 \mathrm{~mm} / \mathrm{min}$

- $a_{e}=0.015 \mathrm{~mm}$

- Grain shape $=c$
Trial 2:

- $\mathrm{v}_{\mathrm{c}}=45 \mathrm{~m} / \mathrm{s}$

- $v_{\mathrm{f}}=2148 \mathrm{~mm} / \mathrm{min}$

- $a_{\mathrm{e}}=0.015$

- Grain shape $=\mathrm{d}$

Total Force $\mathrm{F}_{\mathrm{c}}$

Cutting speed $v_{c}$

Contact time $t_{k}$

[REIM14]

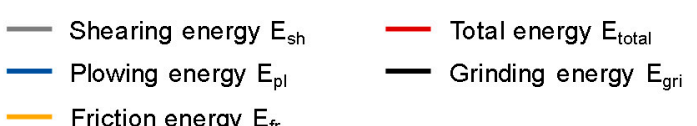

Energies of Each Chip Formation Mechanism
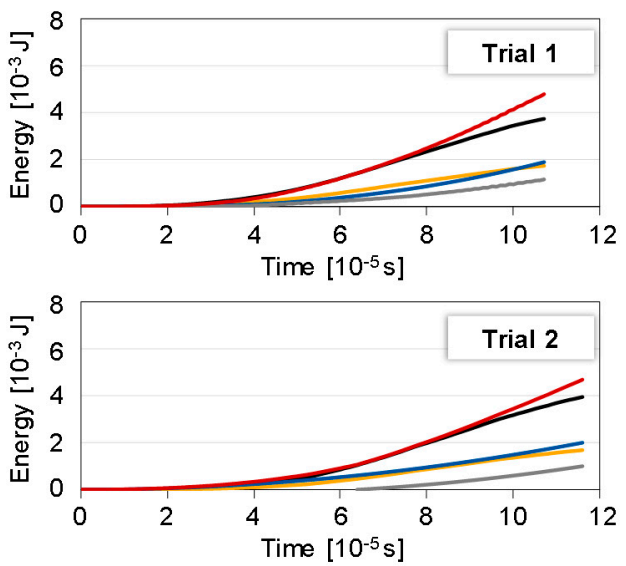

Figure 8. Validation of the adapted Linke energy model.

Trials 1 and 2 were performed with the same process parameters, with exception of the grain shape. The grain shape has a significant influence on the contact conditions between grain and workpiece, in terms of grain cross-section area and grain width. These two parameters, grain cross-section area and grain width, were considered in the calculations of plowing and shearing energy phases. In the following topic, the response of the adapted Linke single-grain energy model to different grain shapes will be further analyzed. In addition, it is known that process parameters can have an influence on the forces during the grinding process, and, consequently, on the process energy. Therefore, the in the following topic, the adapted Linke single-grain energy model will also be further analyzed regarding the influence of process parameters.

\subsection{Application of the Adapted Energy Model}

After the validation of the adapted Linke single-grain energy model showed in the topic before, an investigation of the model was performed, considering the influence the grain shape as well as the process parameter of axial feed rate on each individual energy of the chip formation mechanism. In the experimental trials, grain shape as well as axial feed rate $v_{f}$ were varied. In this topic, the verification of the adapted Linke energy model response regarding the variation of grain shape and axial feed rate is performed.

The influence of the grains shape on the results of the adapted energy model was the first to be analyzed. The shape of the grains was determined in terms of opening angle $\alpha$ and apex angle $\beta$. The influence of the opening angle $\alpha$ was first analyzed, as shown in Figure 9 Two types of opening angle $\alpha$ were investigated. The grains with a high value of opening angle $\alpha$ were called "Grain shape a" and the grains with a low value of opening angle $\alpha$ were called "Grain shape b", left of Figure 9, The apex angle $\beta$ was kept constant.

On the right of Figure 9, diagrams for energy of each chip formation mechanism calculated by the adapted Linke single-grain energy model are shown. The dashed lines represent the energy calculated for "Grain shape a", and the full lines represents the energy calculated for "Grain shape b". It was observed that the alteration in the opening angle $\alpha$ had a small on the total energy $E_{\text {total }}$. The increase of the opening angle $\alpha$ caused a slight decrease in the total energy $E_{\text {total }}$. Friction as well as plowing energy did not show 
significant influence of the opening angle $\alpha$. On the other hand, it was observed that an increase in the opening angle caused a slight decrease of the shearing energy $E_{\mathrm{sh}}$. For both grain shapes, a good correlation between calculated energy $E_{\text {total }}$ and grinding energy $E_{\text {gri }}$ was found.

Description of Trials

- $\mathrm{v}_{\mathrm{c}}=45 \mathrm{~m} / \mathrm{s}$

- $\mathrm{v}_{\mathrm{f}}=2148 \mathrm{~mm} / \mathrm{min}$

Trials 1:

- $\mathrm{a}_{\mathrm{e}}=0.015 \mathrm{~mm}$

- a Grain shape $a>a$ Grain shape $b$

- $\beta$ Grain shape $a=\beta$ Grain shape $b$

---- Grain a

Grain b

Opening

angle $(\alpha)$
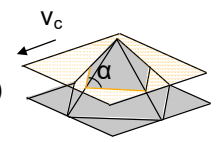

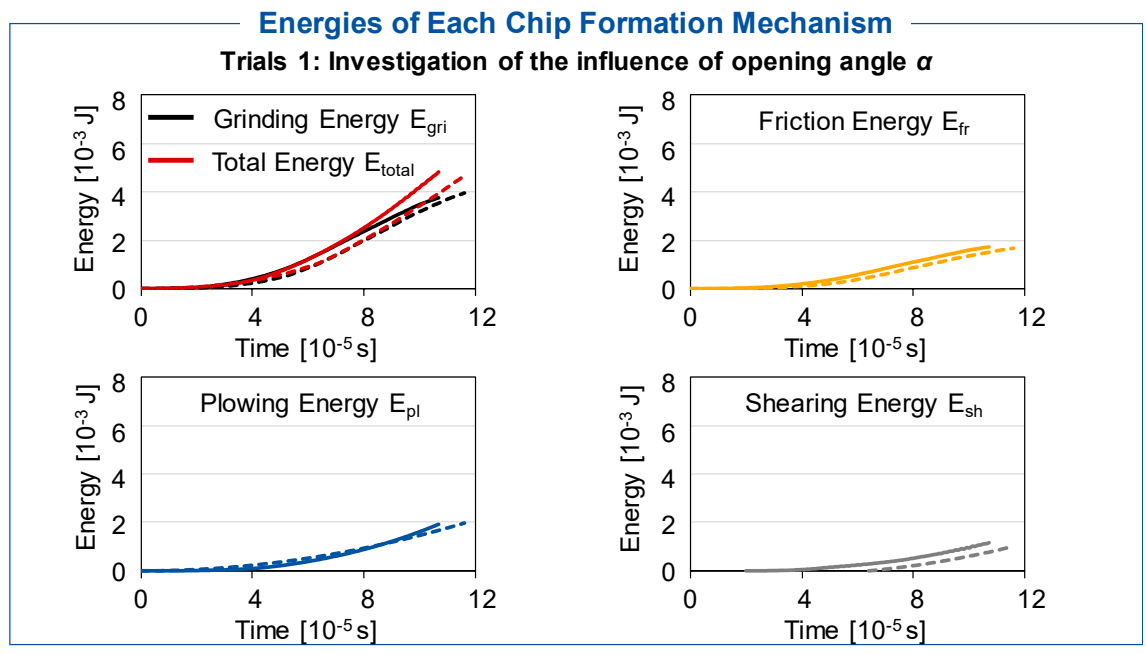

Energies of Each Chip Formation Mechanism

Figure 9. Influence of opening angle $\alpha$ on the energy of each chip formation mechanism.

Next, the influence of the apex angle $\beta$ was analyzed, as shown in Figure 10 Two types of apex angle $\beta$ were investigated. The grains with a high value of apex angle $\beta$ were called "Grain shape $d$ " and the grains with a low value of apex angle $\beta$ were called "Grain shape c", left of Figure 10.

Description of Trials

- $\mathrm{v}_{\mathrm{c}}=45 \mathrm{~m} / \mathrm{s}$

- $v_{\mathrm{f}}=2148 \mathrm{~mm} / \mathrm{min}$

Trials 2:

- $\mathrm{a}_{\mathrm{e}}=0.020$

- $\alpha$ Grain shape $c=\alpha$ Grain shape d

- $\beta$ Grain shape $c<\beta$ Grain shape d

--n- Grain d

Grain c

Apex angle $(\beta)$

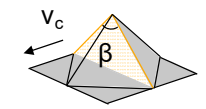

Energies of Each Chip Formation Mechanism Trials 2: Investigation of the influence of apex angle $\beta$
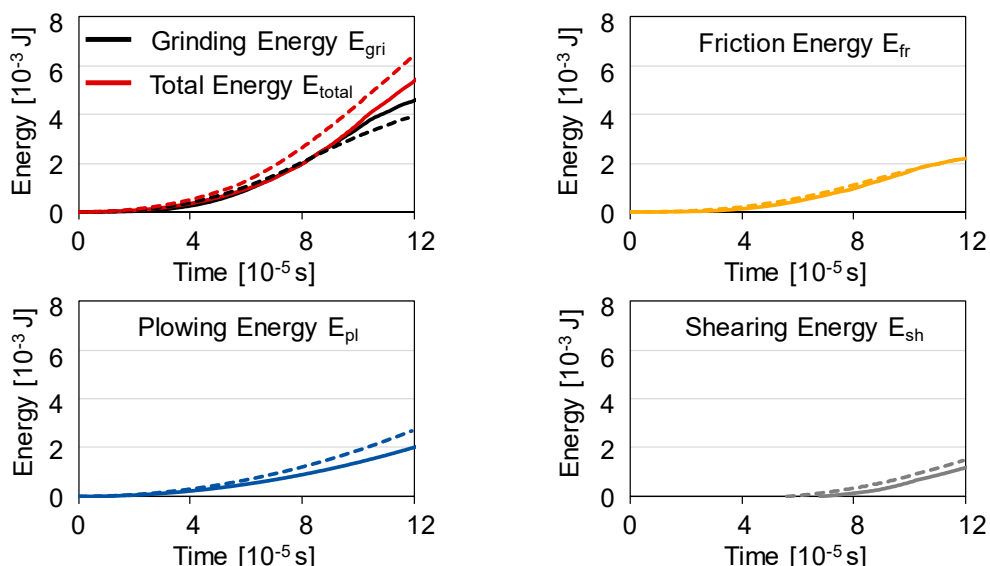

Figure 10. Influence of apex angle $\beta$ on the energy of each chip formation mechanism.

In the test showed in Figure 10, the opening angle $\alpha$ was kept constant. In the diagrams from Trials 2, right of Figure 10, it was observed that the variation in the apex angle $\beta$ had a slight influence especially on the plowing energy $\mathrm{E}_{\mathrm{pl}}$. The increase of the apex angle $\beta$ caused a slight increase in the plowing energy $\mathrm{E}_{\mathrm{pl}}$. Ultimately, the increase of the apex angle $\beta$ caused a slight increase in the total energy $E_{\text {total }}$ as well. The variation in the grain shape in terms of cutting angles, opening angle $\alpha$ and apex angle $\beta$, showed a slight influence on the energies calculated by the adapted energy model. Therefore, the adapted Linke single-grain energy model was able to provide suitable results under variation of the grain shape. 
Next, the influence of axial feed rate $v_{f}$ on the results of the adapted Linke energy model was analyzed, as shown in Figure 11 . Two values of axial feed rate were analyzed, $\mathrm{v}_{\mathrm{f}}=2148 \mathrm{~mm} / \mathrm{min}$ and $\mathrm{v}_{\mathrm{f}}=1074 \mathrm{~mm} / \mathrm{min}$. In the diagrams presented at the right of Figure 11 it was observed that an increase in the axial feed rate $v_{f}$ resulted in an increase in the grinding energy $E_{\text {gri }}$. This result was also detected for the total energy $E_{\text {total }}$, calculated with the adapted energy model. It was also observed that an increase in the axial feed rate $v_{f}$ resulted in an increase in friction energy $E_{f r}$. It is established in the literature that an increase of the axial feed rate $\mathrm{v}_{\mathrm{f}}$ for grinding processes causes an increase in the normal force. Because the calculation of the friction energy $E_{\mathrm{fr}}$ took into consideration the normal force, it is expected to see the increase of the friction energy $E_{\mathrm{fr}}$ due to an increase of the axial feed rate. Regarding the plowing energy $\mathrm{E}_{\mathrm{pl}}$, it was observed that an increase in the axial feed rate $\mathrm{v}_{\mathrm{f}}$ also lead to an increase in the plowing energy $\mathrm{E}_{\mathrm{pl}}$. The same behavior was also observed for the shearing energy $\mathrm{E}_{\mathrm{sh}}$. This result is expected because the calculation of both plowing and shearing energies considered geometric characteristics of the grain engagements such as contact length and chip thickness. These geometric characteristics are directly influenced by the variation of the axial feed rate $\mathrm{v}_{\mathrm{f}}$.

Description of Trials

\section{Trial 1:}

- $\mathrm{v}_{\mathrm{c}}=45 \mathrm{~m} / \mathrm{s}$

- $\mathrm{a}_{\mathrm{e}}=0.015 \mathrm{~mm}$

- Grain shape $=b$

- $\mathrm{v}_{\mathrm{f} 1}=2148 \mathrm{~mm} / \mathrm{min}$

Trial 2:

- $\mathrm{v}_{\mathrm{c}}=45 \mathrm{~m} / \mathrm{s}$

a $a_{e}=0.015 \mathrm{~mm}$

- Grain shape $=b$

- $\mathrm{v}_{\mathrm{f} 2}=1074 \mathrm{~mm} / \mathrm{min}$

Trial 1

---- Trial 2

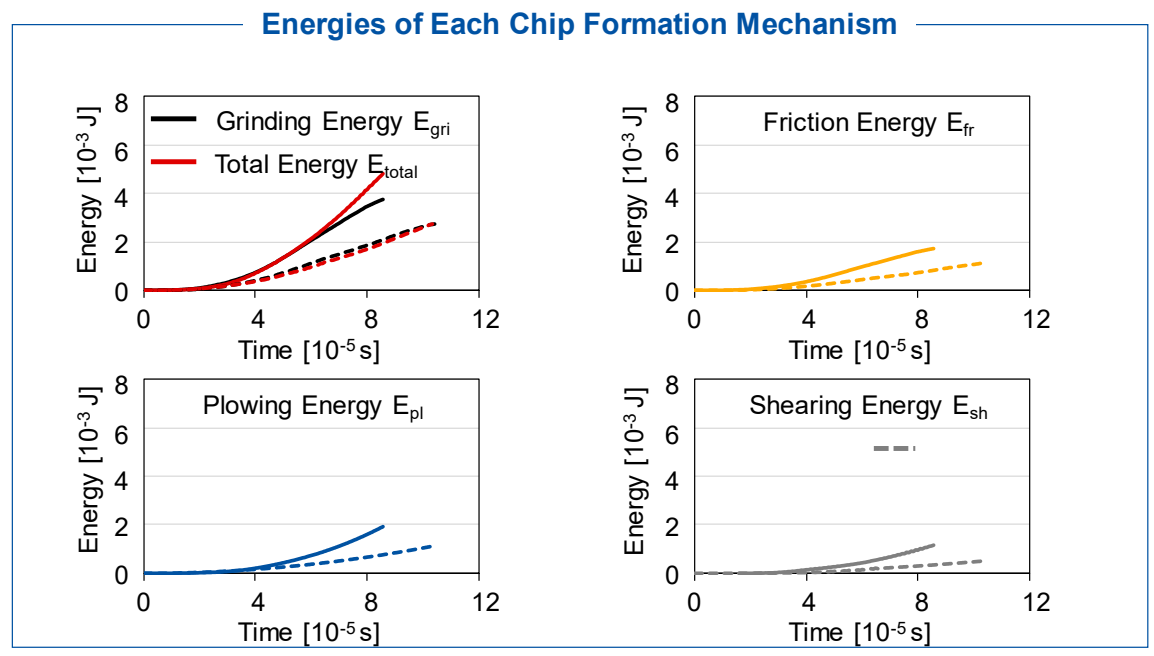

Figure 11. Influence of feed rate on the energy of each chip formation mechanism.

In this topic, the response of the adapted Linke single-grain energy model regarding variation in the grain shape and process parameters was analyzed. The adapted energy model was able to provide sensible results in face of variation of both grain shape and process parameters. In addition, the energy calculated with the adapted energy model was comparable with the grinding energy $E_{\text {gri }}$ calculated from the force measurements obtained from single-grain experimental trials for all test points.

\section{Conclusions}

In order to better understand and control the part of the generated heat that flows into the workpiece during grinding process, it is necessary to calculate the grinding energy considering the different phases of chip formation mechanisms. The objective of this work was to predict the energy generated by the three occurring chip formation mechanisms friction, plowing and shearing during the process of grinding. This objective was reached by adapting the existing energy model from Linke by means of the results of single-grain trials. With the aid of the adapted energy model, the course of the friction, plowing and shearing energy over the chip thickness can be predicted for grinding of case hardened steel with a corundum grain.

The first task of this work was the execution of experimental single-grain trials. In the trials, different grain shapes and process parameters in terms of axial feed rate were investigated. Next, a research for a suitable single-grain energy model which considers 
the different chip formation mechanisms was performed. The single-grain energy model developed by Linke was selected, due to its simplicity and flexibility to different grinding processes kinematics. In the Linke single-grain energy model, the energy of each phase of the chip formation mechanisms was modelled separately and the total energy was the sum of the individual phase energies. Next, an adaptation of the Linke single-grain energy model based on the implementation of data obtained from experimental singlegrain trials. This adaptation required: Evaluation of force measurements, calculation and discretization of contact length, calculation of grain cross-section area from the grain scratch and calculation of the grain width from the grain scratch.

In order to validate the adapted single-grain energy model, grinding energy $E_{\text {gri }}$ was calculated out of the measured cutting force. The calculation of grinding energy $\mathrm{E}_{\text {gri }}$ was performed based on the general concept of energy calculation, using the measurements of the experimental trials as an input. A good correlation between grinding energy $E_{\text {gri }}$ and the energy calculated with the adapted Linke energy model was found. The influence of grain shape as well as axial feed rate on the results given by the adapted single-grain energy model was also investigated. It was observed that the variation in the grain shape did not have a strong influence on the energy. On the other hand, the variation in axial feed rate had not only influence on the total energy $E_{\text {total }}$, but also in the energy of each chip formation mechanism. This result was expected according to the calculation methods used for the determination of each of the energies.

According to the results showed in this work, the adapted Linke single-grain energy model was suitable for the calculation of single-grain energy considering the contributions of the different chip formation mechanisms. For the future, further developments need to be performed for the application of the adapted single-grain energy model on the calculation of the energy of generating gear grinding process. Important inputs of the adapted singlegrain energy model such as contact length, grain cross-section area and grain width need to adapted for the special contact conditions induced by the kinematics of generating gear grinding process. In addition, investigations regarding the micro-interaction of several grains in the grinding contact zone for the process of generating gear grinding needs to be performed. This investigation will provide the possibility of applying the adapted single-grain energy model developed in this work on each of the grains engaging in the material at the grinding contact zone. Ultimately, a better understanding of the energy during the generating gear grinding process will be possible.

Author Contributions: Conceptualization, P.d.O.T. and J.B.; methodology, P.d.O.T.; validation, P.d.O.T. and J.B.; investigation, P.d.O.T.; resources, T.B.; writing—original draft preparation, P.d.O.T.; writing-review and editing, J.B. and T.B.; supervision, J.B. and T.B.; project administration, T.B.; funding acquisition, T.B. All authors have read and agreed to the published version of the manuscript.

Funding: This research was funded by the German Research Foundation (DFG), grant number DFG EXC2023/1-B1.II.

Data Availability Statement: The data presented in this study are available on request from the corresponding author. The data are not publicly available due to privacy.

Conflicts of Interest: The authors declare no conflict of interest.

\section{References}

1. Ophey, M. Modellierung des Schleifschneckenprofilverschleißes Beim Kontinuierlichen Wälzschleifen. Ph.D. Thesis, RWTH Aachen University, Aachen, Germany, 2019.

2. Guo, C.; Yan, C. Thermal modelling an optimization of interrupted grinding. CIRP Ann. Manuf. Technol. 2018, 67, 321-324. [CrossRef]

3. Linke, B.; Garretson, I.; Torner, F.; Seewig, J. Grinding Energy Modelling Based on Friction, Plowing, and Shearing. J. Manuf. Sci. Eng. 2017, 139, 1-11. [CrossRef]

4. Malkin, S. Grinding Technology: Theory and Applications of Machining with Abrasives; American Society of Civil Engineers: Reston, VA, USA, 1989.

5. Malkin, S.; Guo, C. Thermal Analysis of Grinding. CIRP Ann. 2007, 56, 760-782. [CrossRef] 
6. Hahn, E.R. On the Mechanism of the Grinding Process under Plunge Cut Conditions. J. Eng. Ind. 1966, 88, 72-80. [CrossRef]

7. Kountanya, R.; Guo, C. Force and temperature modelling in 5-axis grinding. Procedia Manuf. 2018, 26, 521-529. [CrossRef]

8. Teixeira, P.H.O.; Brecher, C.; Löpenhaus, C. Discretization of the Contact Conditions Considering the Grain Engagement for Generating Gear Grinding. Forsch. Im Ing. 2019, 83, 1739-1748.

9. Ghosh, S.; Chattopadhyay, A.B.; Paul, S. Modelling of Specific Energy Requirement During High-Efficiency Deep Grinding. Int. J. Mach. Tools Manuf. 2008, 48, 1242-1253. [CrossRef]

10. Anderson, D.; Warkentin, A.; Bauer, R. Experimental and Numerical Investigations of Single Abrasive-Grain Cutting. Int. J. Mach. Tools Manuf. 2011, 51, 898-910. [CrossRef]

11. Rowe, W.B. Principles of Modern Grinding Technology; Elsevier Inc.: Oxford, UK, 2014.

12. Jiang, J.; Ge, P.; Sun, S.; Wang, D.; Wang, Y.; Yang, Y. From the Microscopic Interaction Mechanism to the Grinding Temperature Field: An Integrated Modelling on the Grinding Process. Int. J. Mach. Tools Manuf. 2016, 110, 27-42. [CrossRef]

13. Kopalinsky, E. Modelling of Material Removal and Rubbing Processes in Grinding as a Basis for Realistic Determination of Workpiece Temperature Distributions. Wear 1982, 81, 115-134. [CrossRef]

14. Park, H.W.; Liang, S.; Chen, R. Microgrinding Force Predictive Modelling Based on Microscale Single-Grain Interaction Analysis. Int. J. Manuf. Technol. Manag. 2007, 12, 25-38. [CrossRef]

15. Durgumahanti, U.S.; Vijayender Singh, P.; Venkateswara Rao, P. A New Model for Grinding Force Prediction and Analysis. Int. J. Mach. Tools Manuf. 2010, 50, 231-240. [CrossRef]

16. Rasim, M. Modellierung der Wärmeentstehung im Schleifprozess in Abhängigkeit von der Schleifscheibentopographie. Ph.D. Thesis, RWTH Aachen University, Aachen, Germany, 2016.

17. Brown, C.A. Machining of Metals: Fundamentals. Encycl. Mater. Sci. Technol. 2001, 4703-4708. [CrossRef]

18. Reimann, J. Randzonenbeeinflussung Beim Kontinuierlichen Wälzschleifen von Stirnradverzahnungen. Ph.D. Thesis, RWTH Aachen University, Aachen, Germany, 2014. 